\title{
Growth and Excellent Field Emission Properties of GaN Nanopencils and Nanotowers
}

\author{
Cui Zhen, Li Enling \\ Xi'an University of Technology, Xi'an 710048, China
}

\begin{abstract}
Gallium nitride (GaN) nanopencils and nanotowers have been synthesized by a chemical vapor deposition (CVD) method using the reaction of $\mathrm{Ga}_{2} \mathrm{O}_{3}$ and ammonia. The observed morphology of $\mathrm{GaN}$ nanopencils is divided into two parts: the bottom is a nanowire with large diameter; the top is a nanowire with small diameter. The observed morphology of GaN nanotowers is a layer structure. The formation mechanism of GaN nanopencils and nanotowers is a vapor-liquid-solid (VLS) mechanism. The turn on field of $2.6 \mathrm{~V} / \mu \mathrm{m}$ is obtained for GaN nanopencils and the turn on field of $4.1 \mathrm{~V} / \mu \mathrm{m}$ is obtained for GaN nanotowers, which are sufficient for field emission flat panel displays and cold electron sources in display devices. This growth of GaN nanopencils and nanotowers will facilitate flexible design of device architectures for nanoelectronics.
\end{abstract}

Key words: GaN; nanocomposite; field emission properties; functional applications

Gallium nitride $(\mathrm{GaN})$ is a wide band gap $(3.4 \mathrm{eV})$ semiconducting material that has excellent performance, such as optical properties, electrical properties, good thermal stability and mechanical properties. Therefore, GaN has a wide range of applications in optoelectronic and microelectronic devices ${ }^{[1-4]}$. GaN semiconductor material, a promising cathode material for field emission, has small electron affinity $(2.7 \sim 3.3 \mathrm{eV})$, physical and chemical stability, and higher melting point $\left(1500{ }^{\circ} \mathrm{C}\right)$. GaN nanowires have excellent performance of field emission properties as a kind of one-dimensional nanomaterials with high aspect ratio, applied widely in field emission devices ${ }^{[5-8]}$. The field emission properties of $\mathrm{GaN}$ nanowires are not only related to ratio of length to diameter, but also related to morphology. For example, the needlelike GaN nanowires with bicrystalline structure can enhance the field emission properties, and the sharp ends and rough surfaces of the nanowires are responsible for their good field emission properties ${ }^{[9]}$. Grass-like, novel durian-like, and dandelion-like $\mathrm{GaN}$ nanostructure can improve the field emission characteristics as well $^{[10-12]}$.

In this paper, we have reported the fabrication of $\mathrm{GaN}$ nanopencils and nanotowers on a Pt-coated $n$-type Si (111) silicon substrate via CVD method by $\mathrm{Ga}_{2} \mathrm{O}_{3}$ and ammonia. As-synthesized $\mathrm{GaN}$ nanostructures are characterized by $\mathrm{X}$-ray diffraction (XRD) and field emission scanning electron microscope (FESEM). The as-synthesized samples have exhibited impressive field emission properties with a turn-on field $(2.6 \mathrm{~V} / \mu \mathrm{m}$ and $4.1 \mathrm{~V} / \mu \mathrm{m})$, which will facilitate flexible design of device architectures for nanoelectronics.

\section{Experiment}

$\mathrm{GaN}$ nanopencils and nanotowers have been synthesized on Pt-coated $n$-type Si (111) substrate ${ }^{[13]}$ via CVD method. (1) The fabrication experiment of $\mathrm{GaN}$ nanopencils: $\mathrm{Ga}_{2} \mathrm{O}_{3}$ powders and Pt-coated Si wafer were placed in a quartz boat in the distance of $\sim 2 \mathrm{~cm}$ between them and were heated in a constant temperature zone of horizontal tube furnace, and then $\mathrm{N}_{2}$ was introduced for a certain time to remove remaining gas. Subsequently, the furnace was heated to $1150{ }^{\circ} \mathrm{C}$ under a constant flow of $\mathrm{NH}_{3}(400 \mathrm{~mL} / \mathrm{min})$ at the same reaction time (20 min). (2) The fabrication experiment of GaN nanotowers: The $\mathrm{Ga}_{2} \mathrm{O}_{3}$ and $\mathrm{C}$ powders were placed into a quartz boat, from which the Pt-coated Si substrate was placed $2 \mathrm{~cm}$ away.

$\overline{\text { Received date: January 12, }} 2017$

Foundation item: National Natural Science Foundation of China (51042010)

Corresponding author: Cui Zhen, Ph. D., School of Automation and Information Engineering, Xi'an University of Technology, Xi'an 710048, P. R. China, Tel: 0086-29-82312431, E-mail: zcui@xaut.edu.cn 
Then the quartz boat was transferred to the central of the horizontal CVD furnace. The horizontal CVD furnace chamber was purged with $300 \mathrm{~mL} / \mathrm{min}$ of $\mathrm{N}_{2}$ for $20 \mathrm{~min}$. Next, the chamber was heated from room temperature to $1200{ }^{\circ} \mathrm{C}$, at which Ar with $200 \mathrm{~mL} / \mathrm{min}$ was firstly introduced in the system for $10 \mathrm{~min}$ and then $200 \mathrm{~mL} / \mathrm{min} \mathrm{NH}_{3}$ gas was introduced, and maintained $15 \mathrm{~min}$. After reaction, the furnace was cooled down naturally to room temperature, and light yellow products obtained on the substrates were collected and analyzed.

\section{Results and Discussion}

Fig.1 shows the XRD patterns of GaN nanopencils and nanotowers, which reveal the overall crystal structure and phase purity of the nanostructures. As can be seen from Fig.1a and $1 \mathrm{~b}$, the diffraction peaks (100), (002), (101), (102), (110), (103), (112), and (201) are completely consistent with standard card of $\mathrm{GaN}$, and the resulting product has high purity of $\mathrm{GaN}$ wurtzite phase ${ }^{[13]}$. The random orientation of $\mathrm{GaN}$ nanowires were caused by lattice mismatch and thermal conductivity between $\mathrm{GaN}$ and Si substrate ${ }^{[14]}$.

Electron microscopy observations illustrate that $\mathrm{GaN}$ nanostructures are distributed on silicon substrates, as shown in Fig.2. As can be seen from Fig.2a, the piles of $\mathrm{GaN}$ nanostructures aligned on the silicon substrate. The inset in Fig.2a is a pile of GaN nanostructure, which likes a hedgehog lying on the silicon substrate. Fig.2b shows a single GaN nanowire with a thin tip, which is like a pencil. Moreover, a Pt catalyst observed at the end of GaN nanowires indicates that the growth mechanism of GaN nanopencils belongs to VLS mechanism ${ }^{[15]}$. The diameter of GaN nanopencils decreases gradually from $\sim 150 \mathrm{~nm}$ to $\sim 50 \mathrm{~nm}$ along the wire axis, and the length of $\mathrm{GaN}$ nanopencils extends to ten micrometers. Morphology of the sample is similar to that of the $\mathrm{GaN}$ nanopencils which has been reported in our research group ${ }^{[15]}$, however, the diameter of the sample is smaller than that in Ref[15]. The main reason is that the ammonia flow is smaller than that in Ref[15]. As can be seen from Fig.2c, a number of $\mathrm{GaN}$ nanostructures are uniformly distributed on silicon substrates, and the length of GaN nanostructures extends to several micrometers. Fig. $2 \mathrm{~d}$ shows the high-magnification FESEM image of GaN nanostructures from Fig.2c. The morphology of $\mathrm{GaN}$ nanostructure is a layer sturucture, which is like a tower. The diameter of $\mathrm{GaN}$ nanotowers decreases gradually from $\sim 200 \mathrm{~nm}$ to $\sim 100 \mathrm{~nm}$ along the wire axis. Morphology of the sample is similar to that of the $\mathrm{GaN}$ nanowires with layer-structure which has been reported in our research group ${ }^{[13]}$; however, the diameter of the sample is smaller than that in Ref[13]. The main reason is that the time of ammonia is shorter than that in Ref[13]. The growth mechanism of $\mathrm{GaN}$ nanopencils and nanotowers is as the depiction in $\operatorname{Ref}[13,15]$.

The field emission properties of the samples were tested by field emission system shown in Fig.3. By defining ${ }^{[16]}$, the turn on field is the electric field required to produce an emission current density of $0.01 \mathrm{~mA} / \mathrm{cm}^{2}$ whereas the threshold field is the electric field required to produce an emission current density of $1 \mathrm{~mA} / \mathrm{cm}^{2}$. The turn on field of $2.6 \mathrm{~V} / \mu \mathrm{m}$ and threshold field of $7.1 \mathrm{~V} / \mu \mathrm{m}$ are obtained from $\mathrm{GaN}$
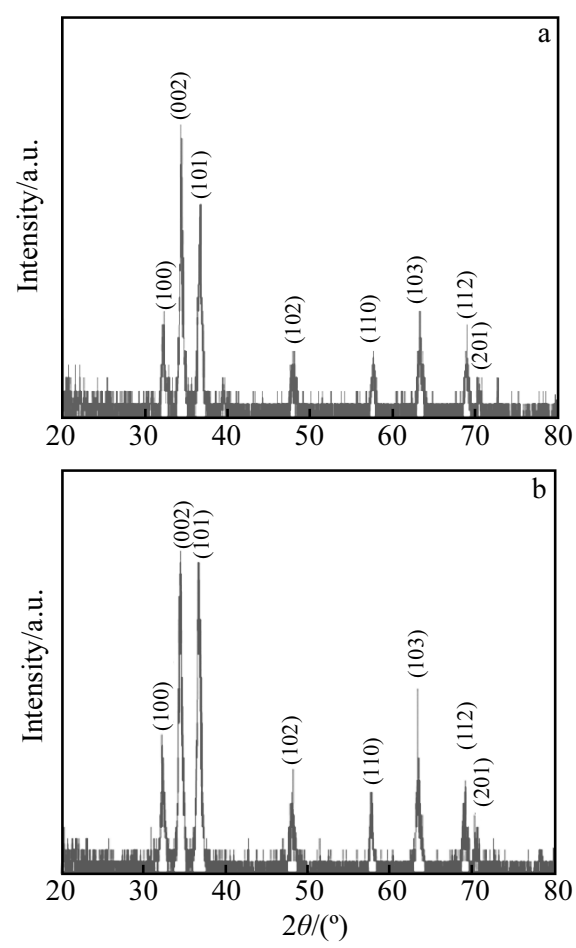

Fig.1 XRD patterns of GaN nanostructures: (a) $\mathrm{GaN}$ nanopencils and (b) GaN nanotowers

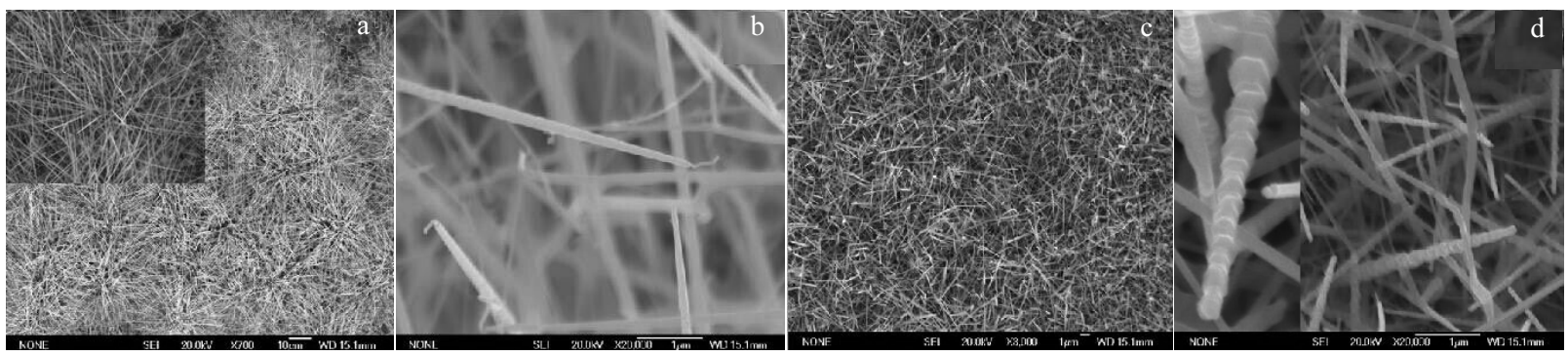

Fig.2 SEM images of GaN nanopencils (a, b) and GaN nanotowers (c, d) 


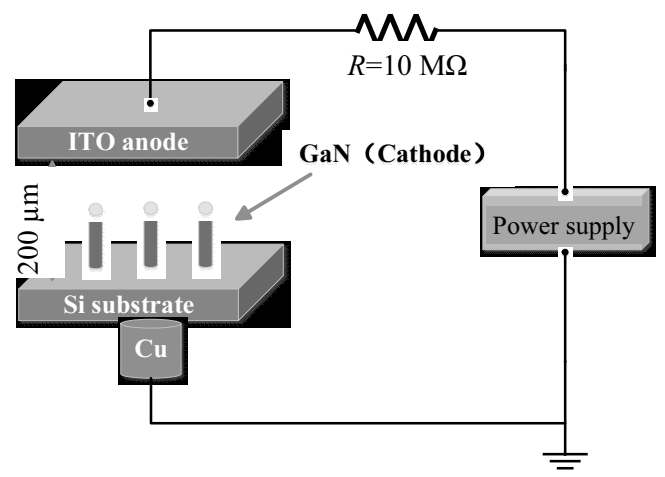

Fig.3 Schematic diagram of field-emission measurements

nanopencils as shown in Fig.4a. The turn on field of $4.1 \mathrm{~V} / \mu \mathrm{m}$ and threshold field of $8.1 \mathrm{~V} / \mu \mathrm{m}$ are obtained from $\mathrm{GaN}$ nanotowers as shown in Fig.4b. The field enhancement factors $(\beta)$ have been calculated to be about 2025 and 1982 for the $\mathrm{GaN}$ nanopencils and nanotowers, respectively. The $F-N$ curves inset in Fig.4a and Fig.4b are linear approximately, which indicate that the field electron emissions of the samples are caused by vacuum tunneling effect ${ }^{[16]}$.

Fig.5 (blue line) shows the stability of $\mathrm{GaN}$ nanopencils within $60 \mathrm{~min}$ under an applied electric field of $4.25 \mathrm{~V} / \mu \mathrm{m}$. The initial current density and the average current density are 125.8 $\mu \mathrm{A} / \mathrm{cm}^{2}$ and $122.2 \mu \mathrm{A} / \mathrm{cm}^{2}$, respectively. No notable current density

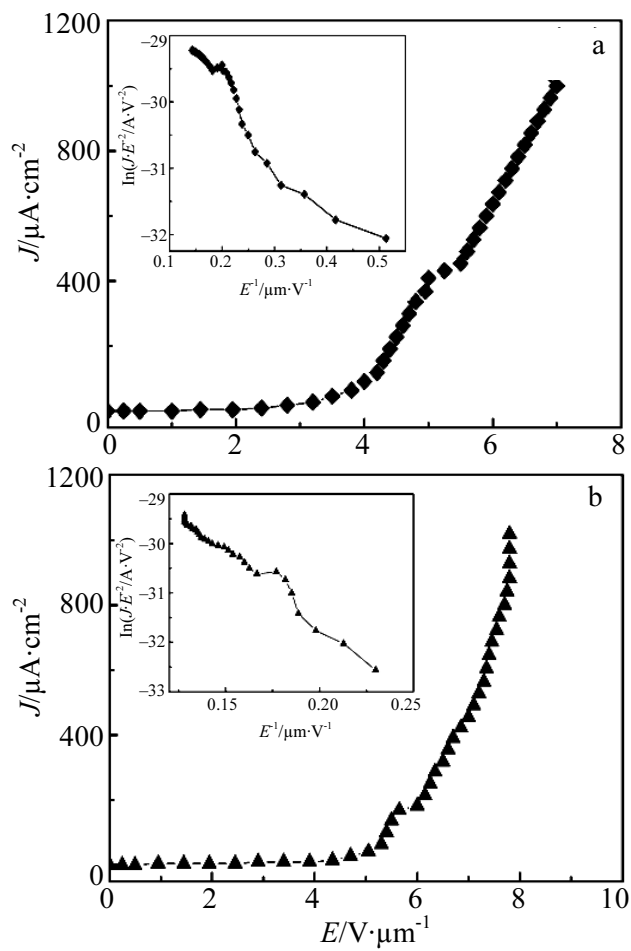

Fig.4 Field emission $J-E$ curve and $F-N$ curve of GaN nanopencils (a) and $\mathrm{GaN}$ nanotowers (b)

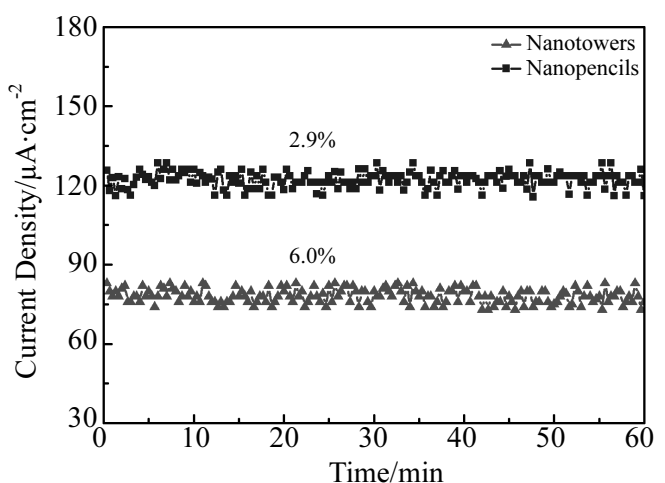

Fig.5 Field emission current density stability of GaN nanopencils and nanotowers

degradation is observed, and the emission current fluctuation is as low as $\sim 2.9 \%$. Fig. 5 (red line) shows the stability of GaN nanotowers within 60 min under an applied electric field of 5.35 $\mathrm{V} / \mu \mathrm{m}$. The initial current density and the average current density are 83.0 and $78.1 \mu \mathrm{A} / \mathrm{cm}^{2}$, respectively. No notable current density degradation is observed, and the emission current fluctuation is as low as $\sim 6.0 \%$. The highly stable field emission current makes $\mathrm{GaN}$ nanopencils and nanotowers as excellent candidates for the cold electron source for the flat display device. Compared with previous reported values of $\mathrm{GaN}$ nanostructure, the turn on field of GaN nanopencils is lower than Ref[5, 8-13,15-23]. We believe this result is due to (1) The morphology of $\mathrm{GaN}$ is like a hedgehog, and the sharp ends of GaN nanopencils benefit to electron emission; (2) The surface of the $\mathrm{GaN}$ nanotowers is a layer structure, so there are numerous edges on the surface of the GaN nanotowers. The numerous surface edges possess high field enhancement factors because the rough surface can remarkably enhance materials' field emission performance ${ }^{[24,25]}$.

\section{Conclusions}

1) The observed morphology of $\mathrm{GaN}$ nanopencils is divided into two parts: the bottom is a nanowire with large diameter; the top is a nanowire with small diameter. The observed morphology of $\mathrm{GaN}$ nanotowers is a layer structure.

2) The formation mechanism of $\mathrm{GaN}$ nanopencils and nanotowers is a vapor-liquid-solid (VLS) mechanism.

3) GaN nanopencils film possesses a low turn-on field of $2.6 \mathrm{~V} / \mu \mathrm{m}$ and $\mathrm{GaN}$ nanotowers film possesses a low turn-on field of $4.1 \mathrm{~V} / \mu \mathrm{m}$. The highly stable field emission current density makes nanopencils and nanotowers as a kind of excellent candidate of cold electron source for the flat display device. This growth of GaN nanopencils and nanotowers will facilitate flexible design of device architectures for nanoelectronics. 


\section{References}

1 Zolper J C, Shul R J, Baca A G et al. Applied Physics Letters[J], 1996, 68(16): 2273

2 Chen Q, Khan M A, Yang J W et al. Applied Physics Letters [J], 1996, 69(6): 794

3 Ponce F, Bour D P. Nature[J], 1997, 386(6623): 351

4 Johnson J C, Choi H J, Knutsen K P et al. Nature Materials[J], 2002, 1(2): 106

$5 \mathrm{Ng}$ D K T, Hong M H, Tan L S et al. Nanotechnology[J], 2007, 18(37): 375707

$6 \mathrm{Ng} \mathrm{D} \mathrm{K} \mathrm{T,} \mathrm{Hong} \mathrm{M} \mathrm{H,} \mathrm{Tan} \mathrm{L} \mathrm{S} \mathrm{et} \mathrm{al.} \mathrm{Applied} \mathrm{Physics} \mathrm{A[J],}$ 2008, 93(3): 685

7 Xiang X, Zhu H. Applied Physics A[J], 2007, 87(4): 651

8 Li E, Cui Z, Dai Y et al. Applied Surface Science[J], 2011, 257(24): 10850

9 Liu B, Bando Y, Tang C et al. The Journal of Physical Chemistry B[J], 2005, 109(36): 17082

10 Nabi G, Cao C, Khan W S et al. Materials Letters[J], 2012, 66(1): 50

11 Nabi G, Cao C, Khan W S et al. Materials Chemistry and Physics[J], 2012, 133(2): 793

12 Nabi G, Cao C, Khan W S et al. Applied Surface Science[J], 2011, 257(23): 10289

13 Cui Z, Li E, Shi W et al. Materials Research Bulletin[J], 2014,
56: 80

14 Seo H W, Bae S Y, Park J et al. The Journal of Chemical Physics[J], 2002, 116(21): 9492

15 Cui Z, Li E, Shi W et al. Ceramics International[J], 2015, 41(4): 6074

16 Nabi G, Cao C, Hussain S et al. Cryst Eng Comm[J], 2012, 14(24): 8492

17 Luo L, Yu K, Zhu Z et al. Materials Letters[J], 2004, 58(22): 2893

18 Dinh D V, Kang S M, Yang J H et al. Journal of Crystal Growth[J], 2009, 311(3): 495

19 Ha B, Seo S H, Cho J H et al. The Journal of Physical Chemistry B $[\mathrm{J}], 2005$, 109(22): 11095

20 Chen C C, Yeh C C, Chen C H et al. Journal of the American Chemical Society[J], 2001, 123(12): 2791

21 Zhao W, Wang R Z, Song Z W et al. The Journal of Physical Chemistry C[J], 2013, 117(3): 1518

22 Liu B D, Bando Y, Tang C C et al. Applied Physics Letters[J], 2005, 87: 073106

23 Li E L, Cui Z, Fu N N et al. Materials Letters[J], 2015, 15: 426

24 Cui Z, Ke X, Li E et al. Materials \& Design[J], 2016, 96: 409

25 Zhang Y, Cui Z, Ding Y et al. Optical and Quantum Electronics[J], 2016, 48(12): 548

\title{
氮化镓纳米铅笔与纳米塔制备及优异场发射性能研究
}

\author{
崔 真, 李恩玲 \\ (西安理工大学, 陕西 西安 710048)
}

\begin{abstract}
摘 要: 通过化学气相沉积法, 用氧化镓和氨气反应成功制备出氮化镓纳米铅笔和纳米塔。通过扫描电镜表征发现氮化镓纳米铅笔分 为两个部分: 底部是一个大直径的纳米线, 顶部是一个小直径的纳米线; 氮化镓纳米塔为层状结构。氮化镓纳米铅笔和纳米塔的形成 机理是气-液-固机制。场发射性能测试显示氮化镓纳米铅笔的开启电场为 $2.6 \mathrm{~V} / \mu \mathrm{m}$, 纳米塔的开启电场为 $4.1 \mathrm{~V} / \mu \mathrm{m}$, 这使得它们可以 用于场发射平板显示及显示装置的冷阴极电子源, 它们还可以使用于设计复杂纳米电子器件。
\end{abstract}

关键词：氮化镓；纳米复合材料；场发射；功能应用

作者简介: 崔 真, 男, 1986 年生, 博士, 西安理工大学自动化与信息工程学院, 陕西 西安 710048, 电话: 029-82312431, E-mail: zcui@xaut.edu.cn 